\title{
Development of a Wind Directly Forced Heat Pump and Its Efficiency Analysis
}

\author{
Ching-Song Jwo, ${ }^{1}$ Zi-Jie Chien, ${ }^{1}$ Yen-Lin Chen, ${ }^{2}$ and Chao-Chun Chien ${ }^{1}$ \\ ${ }^{1}$ Department of Energy and Refrigerating Air-Conditioning Engineering, National Taipei University of Technology, \\ Taipei 10608, Taiwan \\ ${ }^{2}$ Department of Computer Science and Information Engineering, National Taipei University of Technology, Taipei 10608, Taiwan
}

Correspondence should be addressed to Yen-Lin Chen; ylchen@ntut.edu.tw

Received 21 November 2012; Accepted 26 December 2012

Academic Editor: Sih-Li Chen

Copyright (C) 2013 Ching-Song Jwo et al. This is an open access article distributed under the Creative Commons Attribution License, which permits unrestricted use, distribution, and reproduction in any medium, provided the original work is properly cited.

\begin{abstract}
The requirements of providing electric energy through the wind-forced generator to the heat pump for water cooling and hot water heating grow significantly by now. This study proposes a new technique to directly adopt the wind force to drive heat pump systems, which can effectively reduce the energy conversion losses during the processes of wind force energy converting to electric energy and electric energy converting to kinetic energy. The operation of heat pump system transfers between chiller and heat that are controlled by a four-way valve. The theoretical efficiency of the traditional method, whose heat pump is directly forced by wind, is $42.19 \%$. The experimental results indicated average value for cool water producing efficiency of $54.38 \%$ in the outdoor temperature of $35^{\circ} \mathrm{C}$ and the indoor temperature of $25^{\circ} \mathrm{C}$ and the hot water producing efficiency of $52.25 \%$ in the outdoor temperature and the indoor temperature both of $10^{\circ} \mathrm{C}$. We proposed a method which can improve the efficiency over $10 \%$ in both cooling and heating.
\end{abstract}

\section{Introduction}

Heavy energy consumption and environmental pollution have become very serious issues in today's world. Finding and developing new alternative energies has become a very urgent issue. Although an alternative fuel could be found to replace the petroleum oil and resolve the energy crisis problem, the gas waste would pollute the environment, which should be taken into account in the energy issues and environmental protection issues. It is thus a very important subject to develop a new kind of energy [1] that would produce less waste gas. Green energies that can replace fuel energy include wind energy, solar energy, biomass energy, and tidal energy, with the characteristic of being free, natural, free of pollution problems, and inexhaustible. The green energies are best suited to the contemporary needs. Currently, most of the focuses are on the development of wind energy $[2,3]$ and solar energy $[4,5]$. The cost of developing wind force energy is much lower than that for the solar energy and that is the major advantage of wind force energy. For instance, the advanced countries, such as Germany, Denmark, the UK, and the USA have invested in the development of wind force energy [6]. The technology of converting wind force energy to electric energy has been maturely developed with many of the development results being applied to the power utilization in the people's livelihood, commerce, and industry $[7,8]$.

A place with abundant wind energy is the essential condition for the wind turbine. Taiwan is an island country surrounded by sea with many small islands, which is very suitable for wide applications of the wind power generation [9]. Since it is very cold in the winter and very hot in the summer in the seaside environments, it is even suitable to promote the method of driving the heat pump system to produce cool water and hot water directly with the wind force. Figure 1 shows the statistics of the mean wind speeds of several local areas in Taiwan. As can be seen from Figure 1, the mean average wind speeds during all seasons are over $4 \mathrm{~m} / \mathrm{s}$ [10]. This study proposes a new technique to directly adopt the wind force to drive heat pump systems, which can effectively reduce the energy conversion losses during 


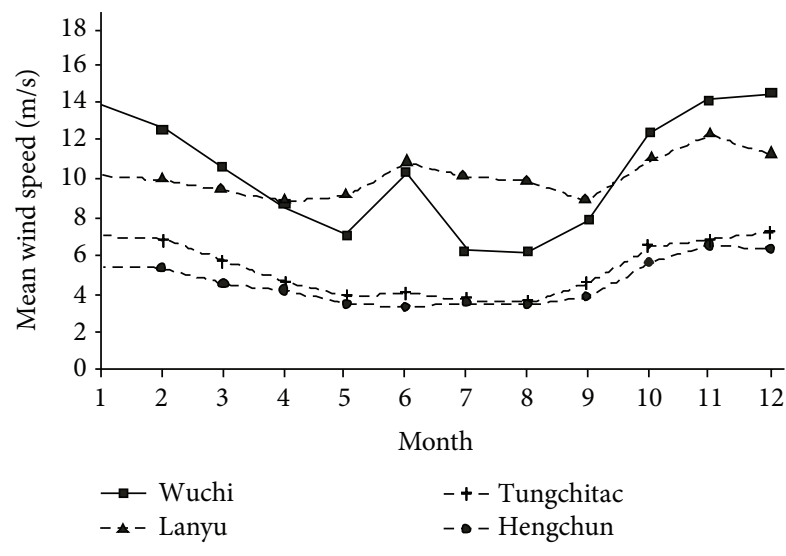

FIGURE 1: Monthly mean wind speed for the four towns in Taiwan.

the processes of wind force energy converting to electric energy and electric energy converting to kinetic energy.

\section{Overview of the Proposed Wind Directly Forced Heat Pump}

The common wind turbines are in two types, namely, the horizontal type and vertical type, with respective advantages and disadvantages. The vertical type is used in the mediumand small-sized wind-driven generators, while the horizontal type is adopted in the large- and medium-sized wind-driven generators. We propose a new technique to directly adopt the wind force to drive heat pump systems, which can effectively reduce the energy conversion losses during the processes of wind force energy converting to electric energy and electric energy converting to kinetic energy. The power transferring the wind force energy indirectly to the heat pump system by the traditional method is calculated with the formula as

$$
\begin{aligned}
p_{\mathrm{hp}} & =\eta_{w} \times \eta_{T 1} \times \eta_{G} \times \eta_{T 2} \times \eta_{M} \times P_{w} \\
& =42.19 \% \times P_{w},
\end{aligned}
$$

where $P_{w}$ is the power of wind force; $p_{\mathrm{hp}}$ is the power when reaching the heat pump system; $\eta_{w}$ is the efficiency of wind turbine; $\eta_{T 1}$ is the efficiency of the transmission between the wind turbine and generator; $\eta_{G}$ is the efficiency of generator; $\eta_{T 2}$ is the transfer efficiency between the generator and electromotor; and $\eta_{M}$ is the efficiency of electromotor.

According to the literatures, $\eta_{w}$ is around 0.59 according to the Betz Law; $\eta_{T 1}$, the efficiency of the transmission, is around 0.95 usually; $\eta_{G}$, the efficiency of generator, is around 0.8 [11]; $\eta_{T 2}$, the transfer efficiency between the generator and electromotor is around 0.97; and $\eta_{M}$, the efficiency of electromotor, is around 0.97. A large quantity of energy losses are generated in the process of converting the wind force energy to electric energy and then the electric energy to mechanical energy driving the compressor to produce the cool energy or hot energy [12]. Using (1), we could get that the total theoretical efficiency of wind energy transfered to thermal energy is $42.19 \%$.
In this study, the wind force could drive the heat pump system directly so that the energy conversion loss could be reduced and the efficiency could be further increased. If an efficient method of the heat pump driving system to generate cool or hot energy directly with the wind force proposed in this study is adopted, then the costs of the generator and generator equipments can be effectively reduced, and the efficiency of converting the wind force energy into the mechanical energy serving a double purpose can also be significantly improved. The power transferring of the wind force energy directly to the heat pump system by the proposed method is calculated with the formula

$$
p_{\mathrm{hp}}=\eta_{w} \times P_{w}
$$

This study tests in the four average wind speeds, namely, $3 \mathrm{~m} / \mathrm{s}, 4 \mathrm{~m} / \mathrm{s}, 5 \mathrm{~m} / \mathrm{s}$, and $6 \mathrm{~m} / \mathrm{s}$, are taken as the basis for performance analysis to verify the feasibility on driving the heat pump system to produce cool water and hot water directly with the wind force.

\section{Analysis of Working Efficiency}

This study analyzes the working efficiency of the cooling and heating achieved by driving the heat pump system directly with the vanes of wind turbine. The theoretical analysis is detailed in the following subsections.

3.1. The Wind Energy. The wind turbine collects the kinetic energy of the wind force through the vanes and outputs the energy through the drive shaft, which is expressed as follows:

$$
E=\frac{1}{2} \rho A V^{3} t
$$

where $\rho$ denotes the air density; $A$ is the area of wind turbine vanes; $V$ represents the wind speed; $t$ is the wind turbine operation time.

3.2. The Heat Pump Energy. The cooling capacity of the heat pump and the heat output to reduce the temperature of the water in the chiller water tank from $t_{c 2}$ to $t_{c 1}$ is expressed as follows:

$$
Q_{c}=m \times s \times \Delta t_{c}=m \times s \times\left(t_{c 2}-t_{c 1}\right),
$$

where $m$ is the water storage weight of the chiller water tank; $s$ is the specific heat of water; $\Delta t_{c}$ is the water temperature difference of the chiller water tank.

The heating capacity of the heat pump and the heat being absorbed to increase the water temperature in the hot water tank from $t_{h 1}$ to $t_{h 2}$ could be formulated as follows:

$$
Q_{h}=m \times s \times \Delta t_{h}=m \times s \times\left(t_{h 2}-t_{h 1}\right),
$$

where $m$ is the water storage weight of the hot water tank; $s$ is the specific heat of water; $\Delta t_{h}$ is the water temperature difference of the hot water tank. 


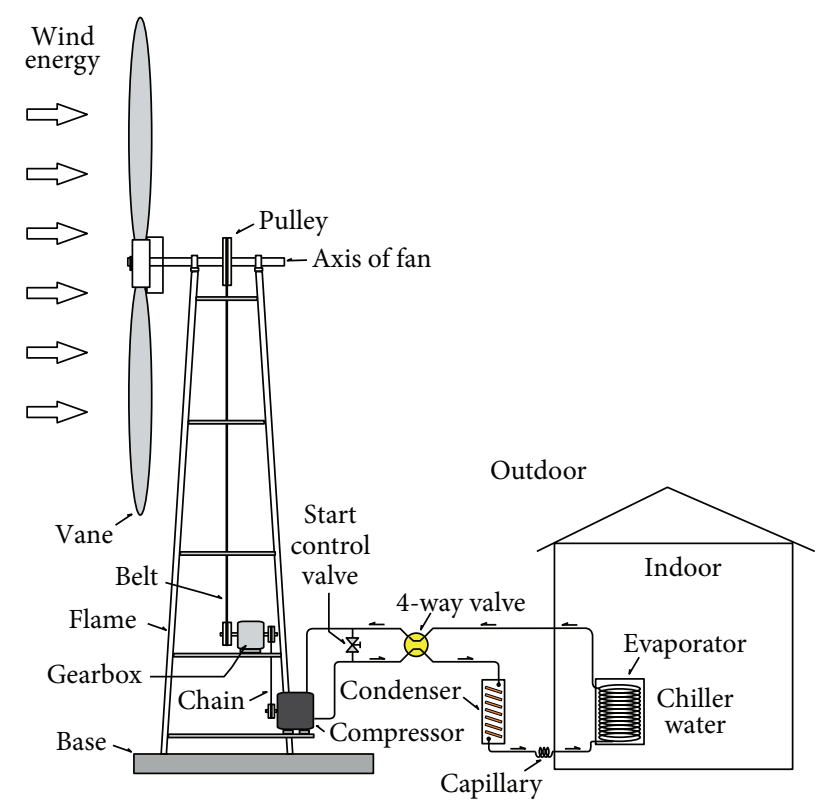

FIGURE 2: Summer model (chiller) of wind directly forced heat pump.

3.3. The Efficiency. The cooling efficiency $\eta_{c}$ or heating efficiency $\eta_{h}$ of the heat pump system driven directly by the vanes of wind turbine could be formulated as follows:

$$
\begin{aligned}
& \eta_{c}=\frac{Q_{c}}{E} \times 100 \%, \\
& \eta_{h}=\frac{Q_{h}}{E} \times 100 \%,
\end{aligned}
$$

where $Q_{c}$ is the cooling capacity of heat pump; $Q_{h}$ is the heating capacity of heat pump; $E$ is the energy output by the drive shaft of wind turbine.

\section{The Proposed Wind Directly Forced Heat Pump}

The experimental equipment of the proposed system consisted of three major parts, namely, the wind turbine, transmission, and heat pump system. The detailed specification, structure, and experimental process are shown as follows.

4.1. The Wind System and Transmission. The wind turbine consisted of three $1.6 \mathrm{~m}$ long fiberglass-reinforced polymers (FRP) vanes. The central axis is affixed onto the frame through the bearing that is installed with a pulley. A transmission is installed underneath the frame with a transmission gear ratio of $1: 5$. The ratio of diameter of the pulley installed on the central axis of wind turbine and that of the pulley of transmission is $5: 1$; therefore, the rotation speed of the wind turbine could be increased by 1:25 to drive the compressor of the heat pump system.

4.2. The Heat Pump System. The heat pump system as depicted in Figures 2 and 3 consisted of an open-type compressor,

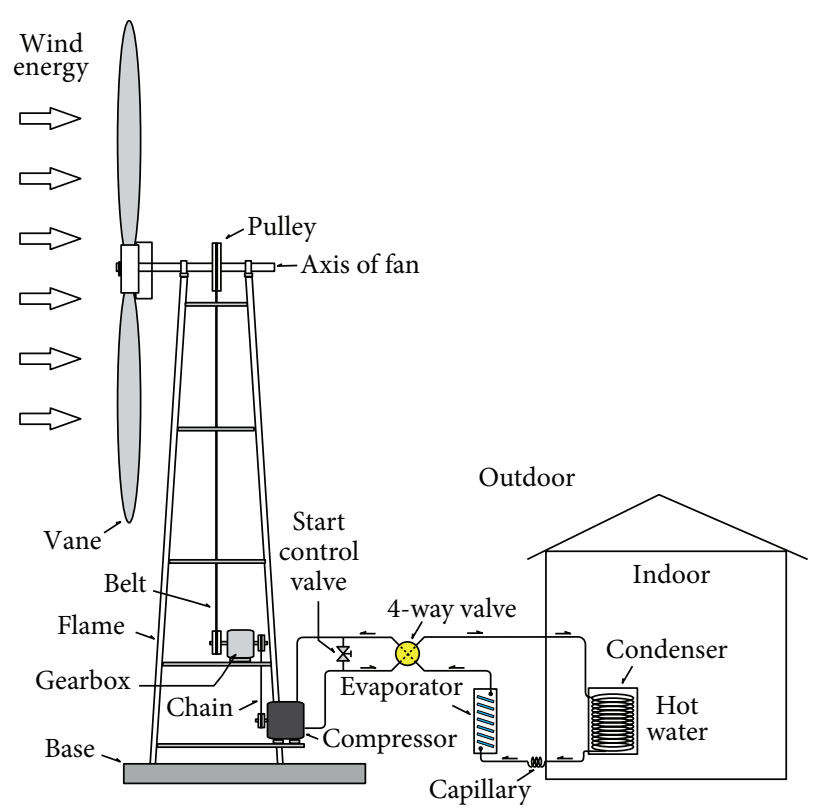

FIGURE 3: Winter model (heat pump) of wind directly forced heat pump.

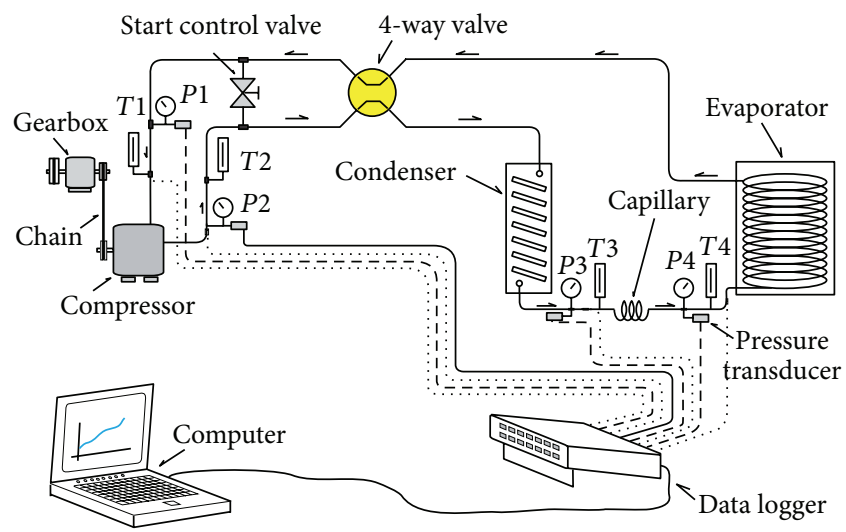

FIgURE 4: The experimental device and measure system.

a condenser, a capillary, an evaporator, a start control valve, and a four-way valve. During the startup stage of the wind turbine, the control valve is open, under the connected discharge end and suction end of the compressor. The compressor starts up during the idle running, and the start control valve is slowly shut off when the rotation speed of the wind turbine reaches its maximal speed and the coolant starts to circulate in the cooling system. The cooling capacity and heating capacity of the heat pump in this experiment are $0.5 \mathrm{~kW}$ and $0.6 \mathrm{~kW}$, respectively.

Two kinds of experimental modes are adopted in the experiment. Figure 2 shows the summer model, under which the indoor heat exchanger serves as the evaporator and the outdoor heat exchanger serves as the condenser. Figure 3 shows the winter model, under which the indoor heat exchanger serves as the condenser and the outdoor heat exchanger serves as the evaporator. The changeover 


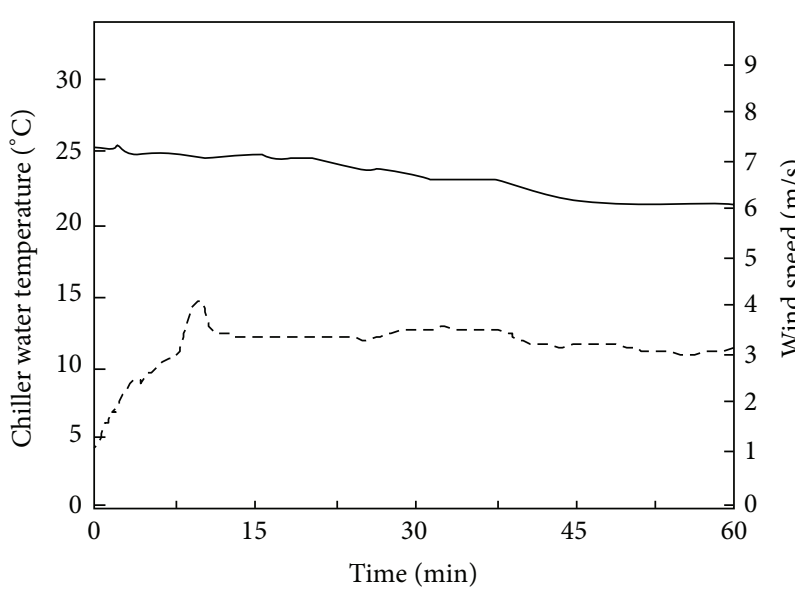

(a) Experiment 1. Average wind speed $3 \mathrm{~m} / \mathrm{s}$

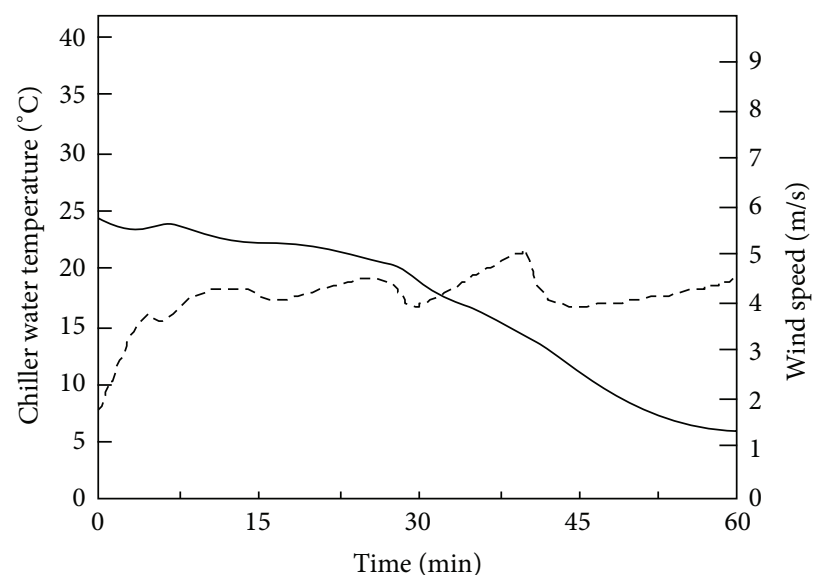

- Water temperature

Wind speed

(c) Experiment 3. Average wind speed $5 \mathrm{~m} / \mathrm{s}$

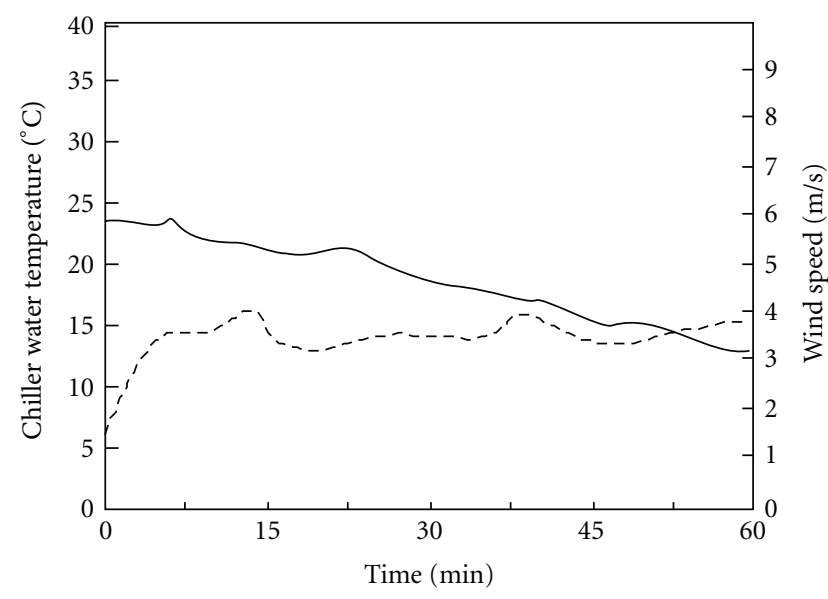

(b) Experiment 2. Average wind speed $4 \mathrm{~m} / \mathrm{s}$

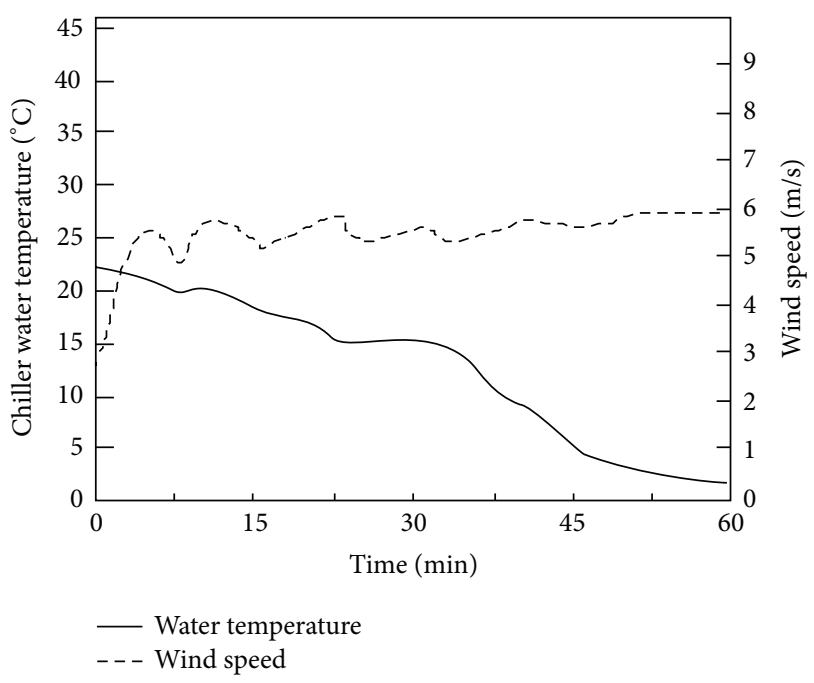

(d) Experiment 4. Average wind speed $6 \mathrm{~m} / \mathrm{s}$

FIGURE 5: Experiment data of summer model (chiller operation) of heat pump.

between the two experimental models is made through operating the 4-way valve. In the summer model, the outdoor temperature of $35^{\circ} \mathrm{C}$ and the indoor temperature of $25^{\circ} \mathrm{C}$; while in the winter model, the outdoor temperature and indoor temperature both are $10^{\circ} \mathrm{C}$.

The experimental device measure system is as shown in Figure 4, where $P 1$ is the suction pressure of the compressor; $P 2$ is the discharge pressure of the compressor; $T 1$ is the suction temperature of the compressor; $T 2$ is the discharge temperature of the compressor; $T 3$ is the outlet temperature of the condenser; $T 4$ is the inlet temperature of the evaporator. The above measuring points are connected with the data logger, and the experiments are performed at the different average wind speeds of $3 \mathrm{~m} / \mathrm{s}, 4 \mathrm{~m} / \mathrm{s}, 5 \mathrm{~m} / \mathrm{s}$, and $6 \mathrm{~m} / \mathrm{s}$, respectively. Here accurate data could be obtained from the computer and be used as the basis for analysis and discussion.

\section{Results and Discussions}

This section summarizes the results obtained performance of the proposed wind directly forced heat pump. The objective is to evaluate the working efficiency and the generalization capability of the wind directly forced heat pump. Summer model (chiller) and winter model (heat pump) of wind directly forced heat pump were examined during 60 minutes by working efficiency at the different average wind speeds of $3 \mathrm{~m} / \mathrm{s}, 4 \mathrm{~m} / \mathrm{s}, 5 \mathrm{~m} / \mathrm{s}$, and $6 \mathrm{~m} / \mathrm{s}$, respectively.

5.1. Working Efficiency in Summer Model (Chiller) of Wind Directly Forced Heat Pump. Figure 2 shows the cool water producing model of the heat pump system driven directly by wind turbine. Figure 5 shows the measurement of the cool water producing capacity of the heat pump system driven directly by the wind turbine. In the experiment of the chiller, the outdoor temperature is $35^{\circ} \mathrm{C}$ and the indoor temperature is $25^{\circ} \mathrm{C}$. The cooling capacity in the summer is measured with a 28 liters water storage tank, and the output capacity of the wind turbine is calculated to obtain the ratio between the cooling capacity of the heat pump system and the output capacity of the wind turbine. The working efficiency of the cooling of the wind turbine is also obtained. Figure 5(a) shows 
TABLE 1: Summation of the experimental condition for the summer model (chiller operation).

\begin{tabular}{lcccc}
\hline Experiment no. & 1 & 2 & 3 & 4 \\
\hline Average wind speed $(\mathrm{m} / \mathrm{s})$ & 3 & 4 & 5 & 6 \\
Total duration $(\mathrm{min})$ & 60 & 60 & 60 & 60 \\
Temperature change $\left({ }^{\circ} \mathrm{C}\right)$ & $25 \sim 23$ & $24 \sim 19$ & $25 \sim 14.5$ & $23 \sim 3$ \\
Cooling energy, $Q_{c}(\mathrm{~kJ})$ & 234.42 & 586.04 & 1230.68 & 2344.16 \\
Wind energy, $E(\mathrm{~kJ})$ & 478.57 & 1134.38 & 2215.58 & 3823.53 \\
Working efficiency, $\eta_{c}$ & 48.99 & 51.66 & 55.55 & 61.30 \\
\hline Climate condition & the outdoor temperature is $35^{\circ} \mathrm{C}$ and \\
& \multicolumn{5}{c}{ the indoor temperature is $25^{\circ} \mathrm{C}$} \\
\hline
\end{tabular}

the data at the average wind speed of $3 \mathrm{~m} / \mathrm{s}$ with the relative data calculated as follows.

$Q_{c}$ is the cool water producing capacity of the heat pump system

$$
\begin{aligned}
Q_{c} & =m \times s \times \Delta t_{c}=28 \times 4.186 \times 2 \\
& =234.42 \mathrm{~kJ},
\end{aligned}
$$

$E$ is the output capacity of the wind turbine

$$
E=\frac{1}{2} \rho A V^{3} t=478.57 \mathrm{~kJ}
$$

$\eta_{c}$ is the efficiency of cooling of the wind turbine

$$
\eta_{c}=\frac{Q_{c}}{E} \times 100 \%=48.99 \% .
$$

Figures $5(\mathrm{~b})-5(\mathrm{~d})$ indicate the wind turbine cooling data at the other three different wind speeds. Table 1 shows the comparison of experimental data of four different kinds of average wind speeds in Figure 5. The results reveal that when the wind speed increases, the energy produced by the wind turbine increases significantly. Thus, the cooling capacity increases, and the efficiency of the wind turbine cooling increases accordingly, as depicted in Figure 6.

\subsection{Efficiency in Winter Model (Heat Pump) of Wind Directly} Forced Heat Pump. In order to change the heat pump system to the hot air producing model, only the direction of the 4way valve needs to be adjusted, as shown in Figure 3. Figure 7 shows the measurement of the hot air producing efficiency of the heat pump system driven directly by the wind turbine. In the experiments of heat pump, the outdoor temperature and the indoor temperature both are $10^{\circ} \mathrm{C}$. The heating capacity in the winter is measured with a 28 liters water storage tank, and the output capacity of the wind turbine is calculated to obtain the ratio between the heating capacity of the heat pump system and the output capacity of the wind turbine. The working efficiency of the heating of the wind turbine is

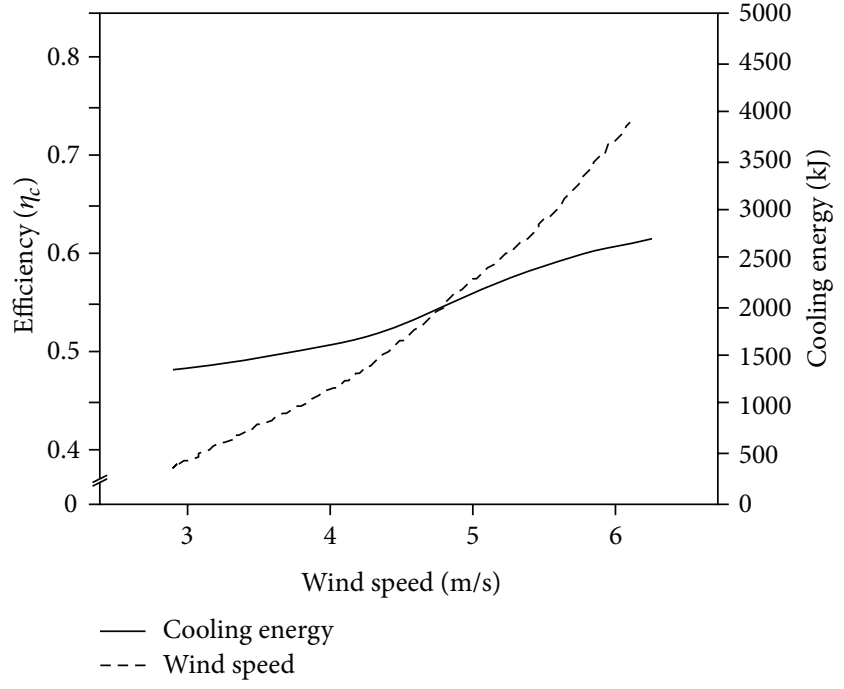

FIGURE 6: The relationship of efficiency and cooling energy versus wind speed for the summer model (chiller operation).

also obtained. Figure 7(a) shows the data at the average wind speed of $3 \mathrm{~m} / \mathrm{s}$ with the relative data calculated as follows.

$Q_{h}$ is the hot air producing capacity of the heat pump system

$$
\begin{aligned}
Q_{h} & =m \times s \times \Delta t_{h}=28 \times 4.186 \times 2.5 \\
& =293.02 \mathrm{~kJ},
\end{aligned}
$$

$E$ is the output capacity of the wind turbine

$$
E=\frac{1}{2} \rho A V^{3} t=478.57 \mathrm{~kJ},
$$

$\eta_{h}$ is the efficiency of heating of the wind turbine

$$
\eta_{h}=\frac{Q_{h}}{E} \times 100 \%=61.23 \% .
$$

Figures $7(\mathrm{~b})-7(\mathrm{~d})$ indicate the wind turbine heating data at the other three different wind speeds. Table 2 shows the comparison of experimental data of four different kinds of wind speeds in Figure 7 . The results reveal that when the wind speed increases, the energy produced by the wind turbine increases significantly. However, the efficiency of the wind turbine heating in Figure 8 decreases. This phenomenon is because the heating is hard to be achieved when the outdoor temperature is only $10^{\circ} \mathrm{C}$, so that the evaporator and outdoor air exchange thermal energy slowly. If heating capacity increases, it means more power will be consumed, and thus the working efficiency goes down consequently.

5.3. Summary of Efficiency of Wind Directly Forced Heat Pump. Tables 1 and 2 summarize the working efficiency of wind turbine cooling at four different wind speeds and the working efficiency of wind turbine heating at four different average wind speeds, namely, $3 \mathrm{~m} / \mathrm{s}, 4 \mathrm{~m} / \mathrm{s}, 5 \mathrm{~m} / \mathrm{s}$, and $6 \mathrm{~m} / \mathrm{s}$. In the summer model (chiller), the outdoor temperature is $35^{\circ} \mathrm{C}$ 


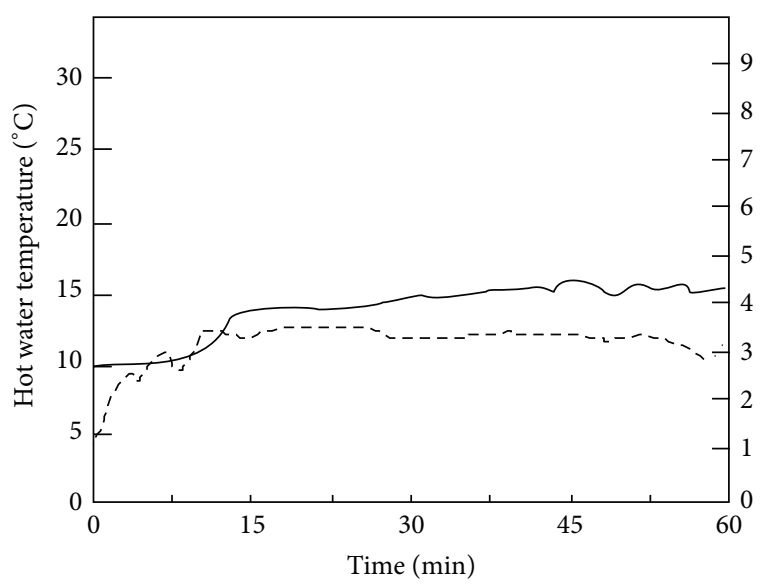

(a) Experiment 1. Average wind speed $3 \mathrm{~m} / \mathrm{s}$

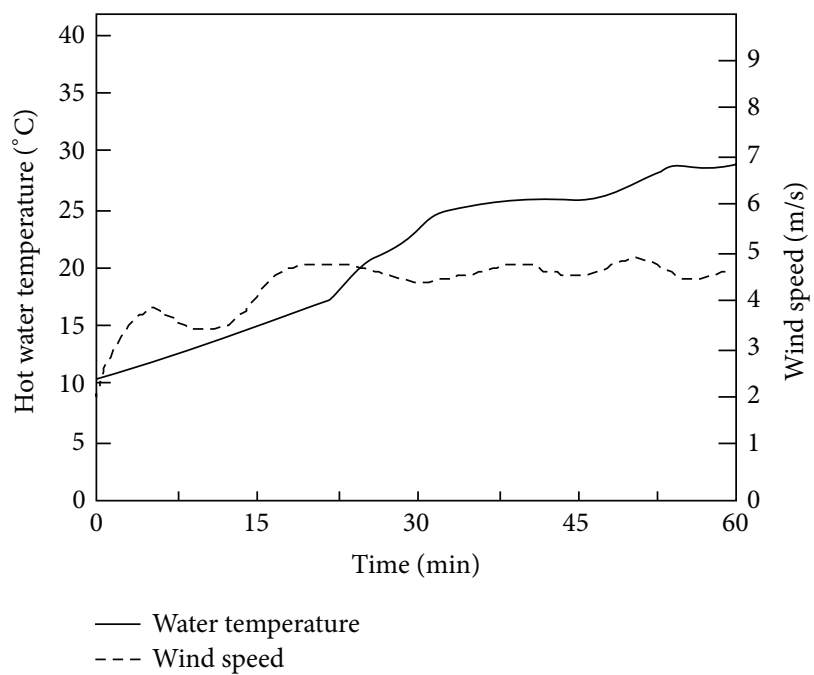

(c) Experiment 3. Average wind speed $5 \mathrm{~m} / \mathrm{s}$

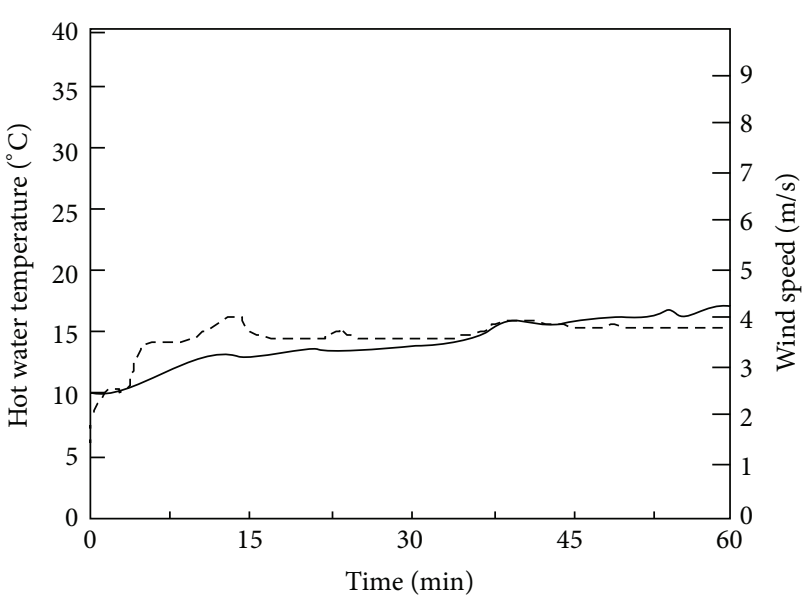

(b) Experiment 2. Average wind speed $4 \mathrm{~m} / \mathrm{s}$

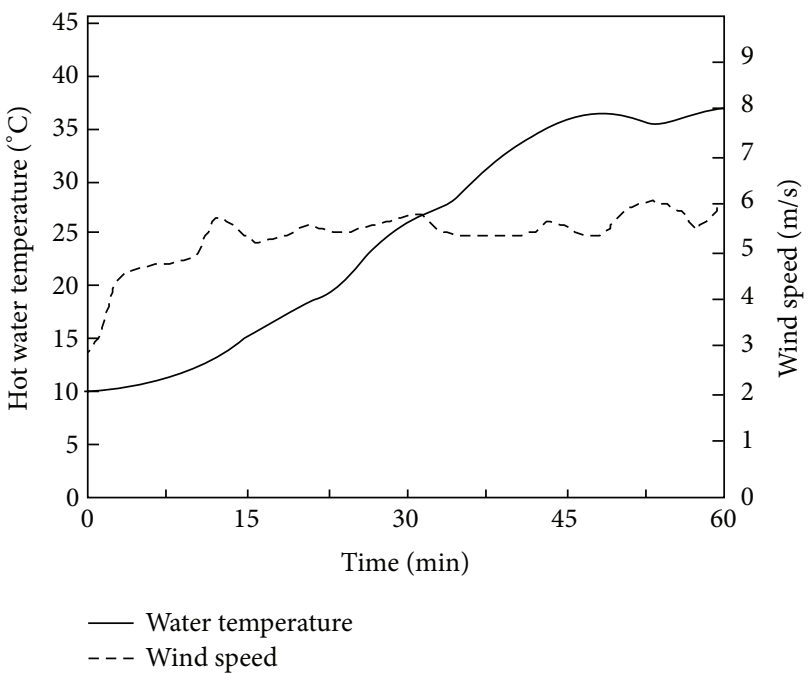

(d) Experiment 4. Average wind speed $6 \mathrm{~m} / \mathrm{s}$

FigURE 7: Experiment data of winter model (heat pump operation) of heat pump.

TABLE 2: Summation of the experimental condition for the winter model (heat pump operation).

\begin{tabular}{lcccc}
\hline Experiment no. & 1 & 2 & 3 & 4 \\
\hline $\begin{array}{l}\text { Average wind speed } \\
(\mathrm{m} / \mathrm{s})\end{array}$ & 3 & 4 & 5 & 6 \\
Total duration (min) & 60 & 60 & 60 & 60 \\
Temperature change $\left({ }^{\circ} \mathrm{C}\right)$ & $10 \sim 12.5$ & $11 \sim 16.5$ & $10 \sim 18.5$ & $10 \sim 25$ \\
Cooling energy, $Q_{h}(\mathrm{~kJ})$ & 293.02 & 644.64 & 996.27 & 1758.12 \\
Wind energy, $E(\mathrm{~kJ})$ & 478.57 & 1134.38 & 2215.58 & 3823.53 \\
Working efficiency, $\eta_{h}$ & 61.23 & 56.83 & 44.96 & 45.98 \\
\hline Climate condition & the outdoor temperature and the indoor \\
& \multicolumn{5}{c}{ temperature both are $10^{\circ} \mathrm{C}$} \\
\hline
\end{tabular}

and the indoor temperature is $25^{\circ} \mathrm{C}$; the working efficiency of the cooling process is $48.99 \%, 51.66 \%, 55.55 \%$, and $61.30 \%$, respectively, whereas the average cooling working efficiency is $54.38 \%$. In the winter model (heat pump), the outdoor temperature and the indoor temperature both are $10^{\circ} \mathrm{C}$; the working efficiency of the heating process is $61.23 \%, 56.83 \%$, $44.96 \%$, and $45.98 \%$, respectively, whereas the average heating working efficiency is $52.25 \%$. The results verify that the heating efficiency is lower than the cooling efficiency. If other heat sources like underground heat source, solar energy, and other waste heat are available, then the heat pump heating efficiency could be further improved.

\section{Conclusions}

The experiment results suggested that driving the heat pump system directly with the wind force can reduce the energy conversion losses during the processes of wind force energy converting to electric energy and electric energy converting to kinetic energy. Taking the air-conditioner load out of the electric load could reduce the equipment capacity of the power distribution project. The experimental results verified that the cool water producing efficiency of the heat pump 


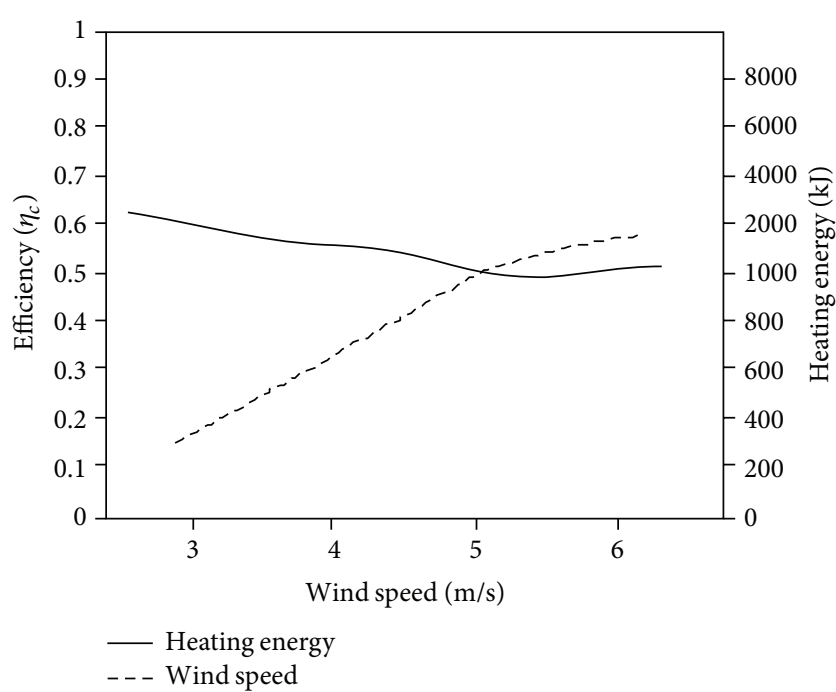

Figure 8: The relationship of efficiency and cooling energy versus wind speed for the winter model (heat pump operation).

system driven directly by wind force is $54.38 \%$ in the outdoor temperature of $35^{\circ} \mathrm{C}$ and the indoor temperature of $25^{\circ} \mathrm{C}$; and the hot water producing efficiency is $52.25 \%$ in the outdoor temperature and indoor temperature both of $10^{\circ} \mathrm{C}$. The proposed method compared with traditional method which theoretical efficiency is $42.19 \%$ can significantly improve the efficiency by over $10 \%$ in both cooling and heating processes. By the time this technology is maturely developed, it could be promoted to the areas with a large quantity of wind farms, such as islands, coast, desert, and high-rise buildings to achieve the purpose of energy conservation and carbon reduction.

\section{Nomenclature}

\begin{tabular}{|c|c|}
\hline$p_{\mathrm{hp}}:$ & $\begin{array}{l}\text { Power when reaching the heat } \\
\text { pump }(\mathrm{kJ})\end{array}$ \\
\hline$P_{w}:$ & Power of wind force $(\mathrm{kJ})$ \\
\hline$\eta_{w}:$ & Efficiency of wind turbine \\
\hline$\eta_{T 1}:$ & $\begin{array}{l}\text { Efficiency of transmission between } \\
\text { wind turbine and generator }\end{array}$ \\
\hline$\eta_{G}:$ & Efficiency of generator \\
\hline$\eta_{T 2}:$ & $\begin{array}{l}\text { Transfer efficiency between generator } \\
\text { and electromotor }\end{array}$ \\
\hline$\eta_{M}:$ & Efficiency of electromotor \\
\hline$\eta_{c}:$ & Cooling efficiency \\
\hline$\eta_{h}:$ & Heating efficiency \\
\hline$E:$ & Wind energy $(\mathrm{kJ})$ \\
\hline$\rho:$ & Air density $\left(\mathrm{kg} / \mathrm{m}^{3}\right)$ \\
\hline A: & Area of wind turbine vanes $\left(\mathrm{m}^{3}\right)$ \\
\hline$V:$ & Wind speed $(\mathrm{m} / \mathrm{s})$ \\
\hline$t:$ & Wind turbine operation time (s) \\
\hline$Q_{c}:$ & Cooling capacity (kJ) \\
\hline$Q_{h}:$ & Heating capacity (kJ) \\
\hline$m:$ & Water storage weight $(\mathrm{kg})$ \\
\hline$s:$ & Specific heat of water \\
\hline
\end{tabular}

$\Delta t_{c}: \quad$ Temperature of the water in the chiller water tank from $t_{\mathrm{c} 2}$ to $t_{c 1}$

$\Delta t_{h}$ : Temperature of the water in the hot water tank from $t_{h 1}$ to $t_{h 2}$.

\section{Acknowledgment}

This paper is financially sponsored by the National Science Council under Grants NSC-101-2622-E-027-025-CC3, NSC101-2219-E-027-006, and NSC-99-2221-E-027-069-MY3.

\section{References}

[1] H. Holttinen, "Optimal electricity market for wind power," Energy Policy, vol. 33, no. 16, pp. 2052-2063, 2005.

[2] M. Esteban and D. Leary, "Current developments and future prospects of offshore wind and ocean energy," Applied Energy, vol. 90, pp. 128-136, 2012.

[3] R. W. Y. Habash, V. Groza, Y. Yang, C. Blouin, and P. Guillemette, "Performance of a contrarotating small wind energy converter," ISRN Mechanical Engineering, vol. 2011, Article ID 828739, 10 pages, 2011.

[4] Y. Bai, T. T. Chow, C. Ménézo, and P. Dupeyrat, "Analysis of a hybrid PV/Thermal solar-assisted heat pump system for sports center water heating application," International Journal of Photoenergy, vol. 2012, Article ID 265838, 13 pages, 2012.

[5] L. Q. Liu, Z. X. Wang, H. Q. Zhang, and Y. C. Xue, "Solar energy development in China-a review," Renewable and Sustainable Energy Reviews, vol. 14, no. 1, pp. 301-311, 2010.

[6] J. B. Welch and A. Venkateswaran, "The dual sustainability of wind energy," Renewable and Sustainable Energy Reviews, vol. 13, no. 5, pp. 1121-1126, 2009.

[7] I. Argatov and R. Silvennoinen, "Energy conversion efficiency of the pumping kite wind generator," Renewable Energy, vol. 35, no. 5, pp. 1052-1060, 2010.

[8] P. Flores, A. Tapia, and G. Tapia, "Application of a control algorithm for wind speed prediction and active power generation," Renewable Energy, vol. 30, no. 4, pp. 523-536, 2005.

[9] C. J. Lin, O. S. Yu, C. L. Chang, Y. H. Liu, Y. F. Chuang, and Y. L. Lin, "Challenges of wind farms connection to future power systems in Taiwan," Renewable Energy, vol. 34, no. 8, pp. 19261930, 2009.

[10] T. J. Chang, Y. T. Wu, H. Y. Hsu, C. R. Chu, and C. M. Liao, "Assessment of wind characteristics and wind turbine characteristics in Taiwan," Renewable Energy, vol. 28, no. 6, pp. 851-871, 2003.

[11] J. F. Manwell, J. G. McGowan, and A. L. Rogers, Wind Energy Explained: Theory, Design and Application, John Wiley \& Sons, New Jersey, NJ, USA, 2002.

[12] C. C. Ting, J. N. Lee, and C. H. Shen, "Development of a wind forced chiller and its efficiency analysis," Applied Energy, vol. 85, no. 12, pp. 1190-1197, 2008. 

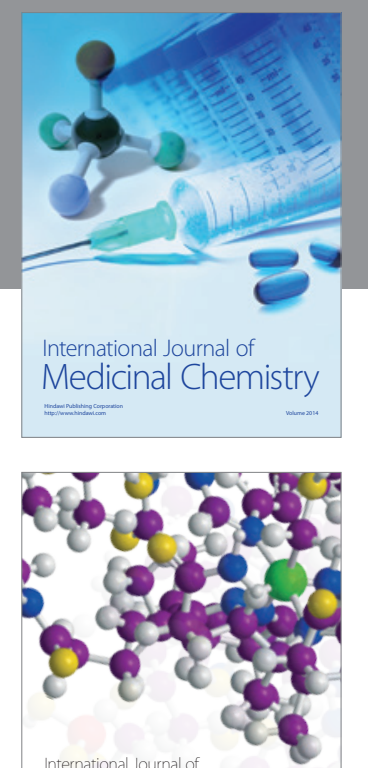

\section{Carbohydrate} Chemistry

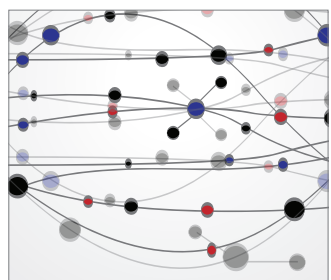

The Scientific World Journal
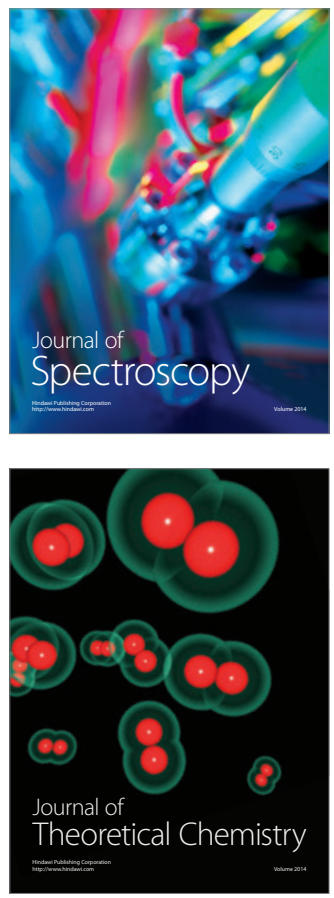
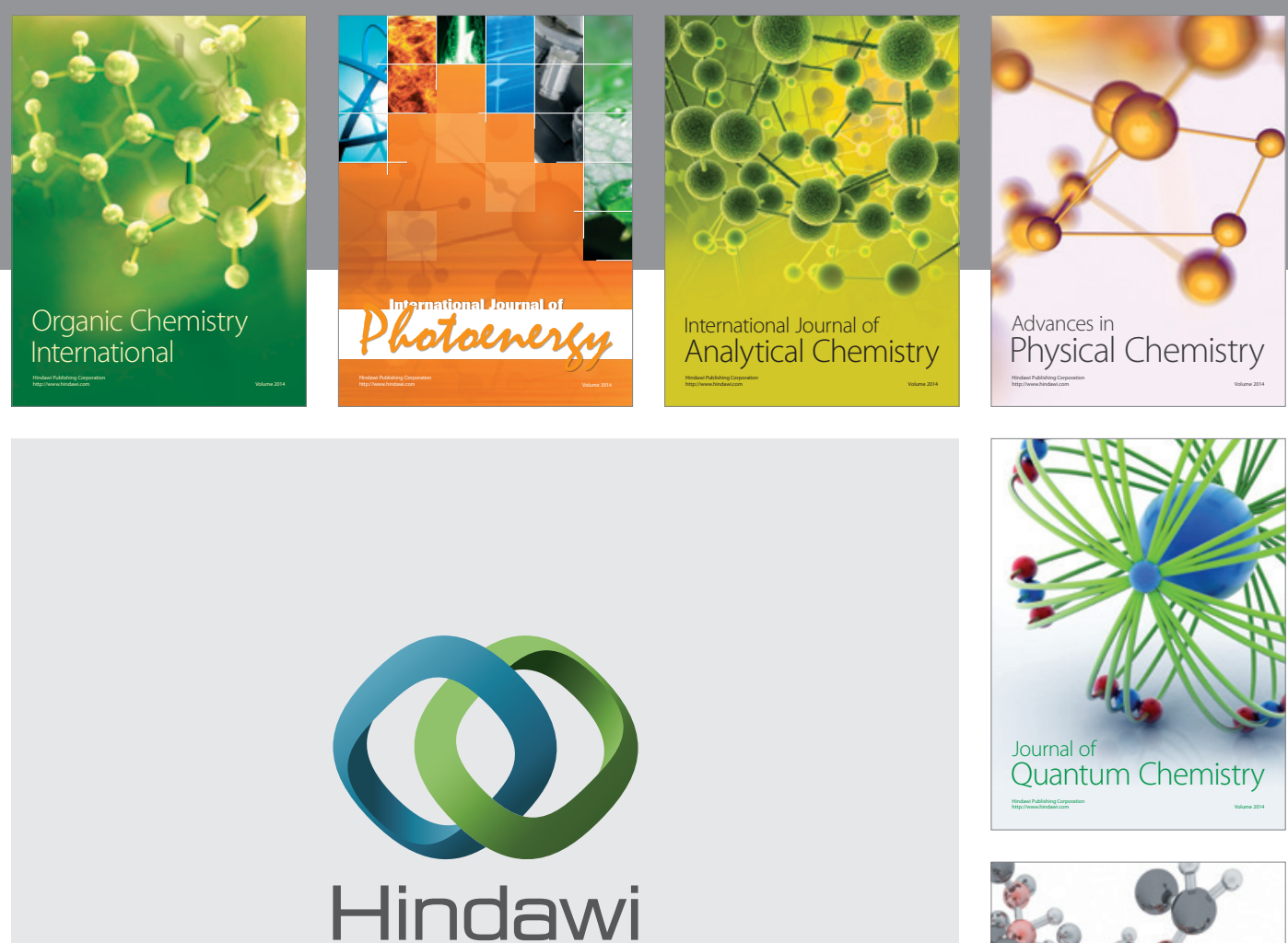

Submit your manuscripts at

http://www.hindawi.com

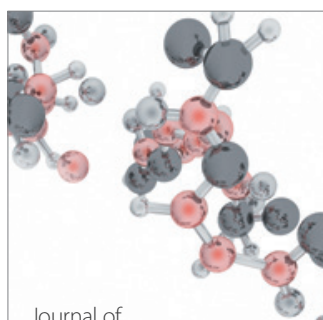

Analytical Methods

in Chemistry

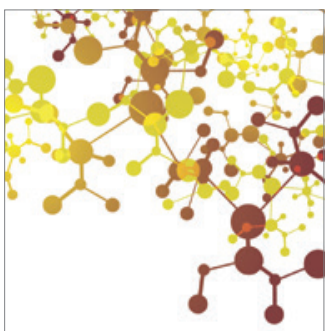

Journal of

Applied Chemistry

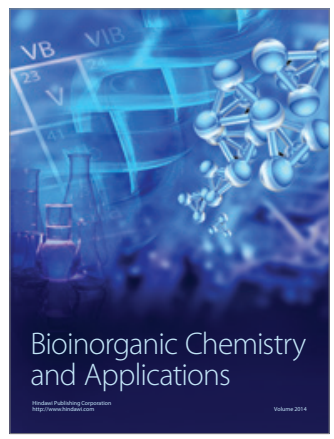

Inorganic Chemistry
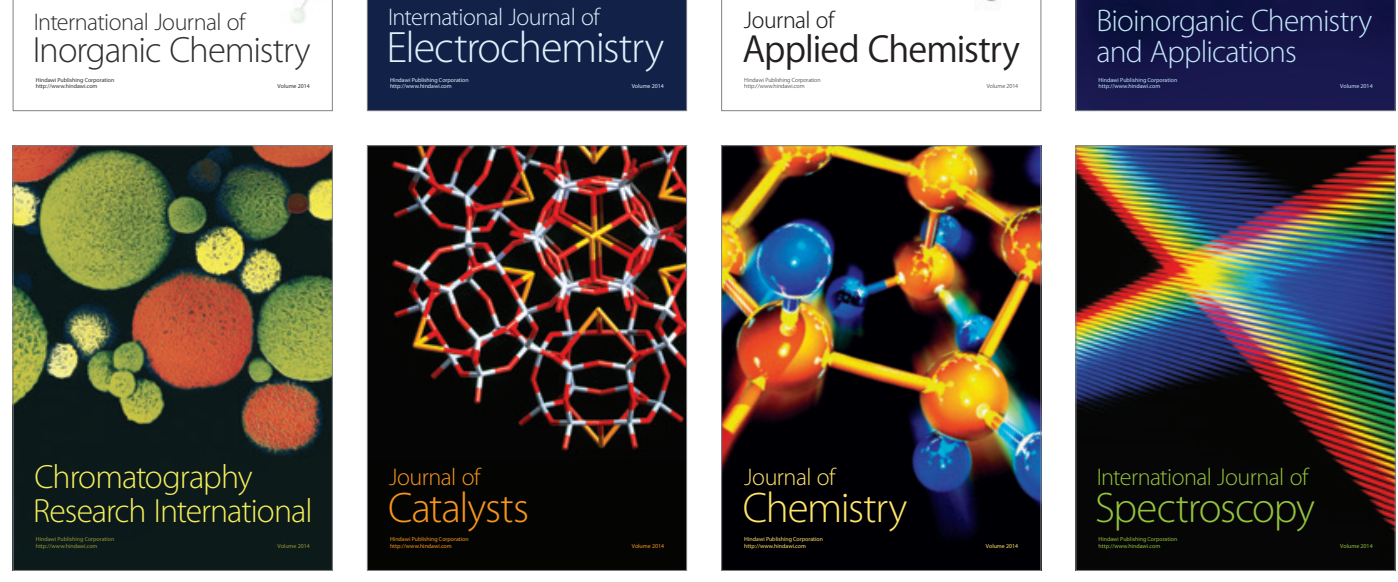